\title{
A dívida e a diferença. Reflexões a respeito da reciprocidade
}

\author{
Jorge Luiz Mattar Villela \\ Doutorando em Antropologia Social - Museu Nacional
}

\begin{abstract}
RESUMO: O objetivo deste artigo é propor alternativas para se pensar o dom, desprendidas das noções de equivalência, homeostase, dialética e reconhecimento; que, como sugere o presente texto, são centrais nas mais variadas leituras do Ensaio sobre o dom assim como em todos os usos que se faz da reciprocidade. Para tal, lançou-se mão dos conceitos apresentados por Nietzsche em $A$ genealogia da moral e dos conceitos de Gilles Deleuze e Felix Guattari, autores que combatem o hegelianismo subjacente nas noções acima referidas.
\end{abstract}

PALAVRAS-CHAVE: Reciprocidade, dom, teoria antropológica, Nietzsche.

\section{Introdução}

Como se apresentam diante dos leitores, iniciados ou não nas artes das ciências humanas, as relações através das quais os homens fazem circular entre si coisas e serviços? Para uma ciência como a antropologia, elas aparecem denominadas com um nome pomposo, reciprocidade; com um nome composto, relações de dom e contra-dom; com um nome equívoco, troca de dons; com um nome sintético, troca. Eis aí, seguramente, uma lista incompleta. Para os não-iniciados, tais relações aparecem com nomes menos belos, porém igualmente eficazes: "toma lá-dá-cá", troca, uma mão lava a outra, troca de favores, etc. 
Sob a nomenclatura referida, escondem-se alguns princípios, dificilmente reveláveis, a custo visíveis a olho nu. Os princípios em questão são: equivalência, equilíbrio, indiferenciado. Subjacente à reciprocidade, ao dom e ao contra-dom, conforme sua interpretação e descrição por antropólogos, etnólogos e etnógrafos, está o antigo interesse em desvendar a inércia social, a estabilidade, o momento de Ser; desejo de toda e cada formação social. Partindo do texto de Mauss, mas baseado em alguns estudos clássicos sobre o tema da reciprocidade, procurarei mostrar como antropólogos perseguiram a todo preço e a todo risco a chave da homeostase social, em detrimento do desequilíbrio das forças postas em relação nos diversos contextos sociais que serviram de base para a construção destas teorias.

\section{O “Ensaio sobre o dom" - prévias}

Preocupações de cunho jurídico sobre a circulação de bens e serviços antecederam em muito o autor do "Ensaio sobre o dom". Pode-se, como fez Pierre Beaucage (1995) ou Anette Weiner (1992), remontar ao século XVII com Hobbes e Locke, ou ao XVIII com Rousseau e Adam Smith. Sem interesse propriamente histórico, ater-me-ei a alguns trabalhos do próprio Mauss em torno deste problema.

Como dissera Lévi-Strauss (1993), os interesses de Mauss sobre o problema do dom remontam a muitos anos antes da publicação do Ensaio, cuja publicação é antecipada cerca de vinte anos por textos envolvendo o tema da reciprocidade e da circulação de dons. Em 1904 Mauss publica, no Année Sociologique, "Os esquimós". Em 1910 aparece na mesma revista um artigo sobre os Haïda e os Tlingit e, em 1913, um outro escrito a respeito das organizações tribais da Melanésia. Quase todos estes trabalhos são o resultado de cursos dados na École Pratique des Hautes Études, cujo conteúdo eram etnografias de autores anglosaxônicos e, como não se pode esquecer, de Franz Boas. Os temas principais são as prestações jurídicas, religiosas e econômicas do 
Revista de Antropologia, São Paulo, USP, 2001, v. 44 nº 1.

Noroeste americano, como no caso dos cursos de 1910-11 e 1911-12. Também no curso de 1912-13, no qual desenvolveu o problema das formas primitivas de contratos coletivos na Melanésia, já esquematizava uma comparação com o potlatch norte-americano ${ }^{1}$.

Mas esta lista, incompleta como a anterior, não se esgota aí. Os anos de 1920 vieram encontrar um Mauss ainda mais interessado nos problemas dos contratos e das prestações. Dois textos, também reunidos por Victor Karady (1994), são especialmente relevantes para o nosso problema: "Uma forma antiga de contrato entre os Trácios", de 1921, e "Gift-gift", de 1924.

O "Ensaio sobre o dom. Forma e razão da troca nas sociedades arcaicas" foi publicado em 1925. É dispensável ensaiar aqui uma leitura ortodoxa do "Ensaio", dadas as inúmeras e brilhantes leituras e interpretações, complementos e críticas célebres tecidas a seu respeito ao longo dos 75 anos que nos separam do seu surgimento. No entanto, convém que se passe brevemente por algumas dessas mesmas críticas, leituras e complementos para que se observe de que modo o artigo de Mauss foi recortado. Entendo que essas leituras críticas ou complementares fizeram sobressair uma perspectiva na qual domina o sentido dialético da reciprocidade.

\section{O ensaio dos antropólogos: críticas e complementos}

Genericamente, os autores que se debruçaram sobre o tema da reciprocidade comungam de um mesmo pão, que se pode chamar, em duas palavras, de equilíbrio e estabilidade. Ao não se tratar de estabelecer avanços ou retrocessos, evoluções ou retificações presentes no conjunto das diversas leituras, fica dispensada uma apresentação cronológica das críticas, dos comentários e dos complementos feitos à obra de Mauss.

Comecemos então pela mais célebre, mais rentável, mais transformadora e influente das leituras do Ensaio ${ }^{2}$. Em sua "Introdução à obra de Marcel Mauss", não tão laudatória quanto a apresentação que faz 
em "A sociologia francesa" (1947), Lévi-Strauss não se limita a "introduzir", mas sobretudo a criticar alguns aspectos e, antes de mais nada, apresentar alguns princípios da obra de Mauss. Famosas são as passagens em que Lévi-Strauss mostra que Mauss atingiu o umbral da análise estrutural, da conjugação entre parentesco e linguagem, domínios entre os quais teria mesmo notado analogias possíveis e que

puderam permitir descobrir as regras precisas segundo as quais se formam em qualquer tipo de sociedade, ciclos de reciprocidade cujos leis mecânicas são doravante conhecidas, permitindo o emprego do raciocínio dedutivo em um domínio que parecia submetido ao arbitrário mais completo. (Lévi-Strauss, 1993: XXXVI)

Foi Mauss, segundo Lévi-Strauss, quem liberou a idéia do social como sistema. Liberando assim um novo tipo de compreensão da sociedade: "pela primeira vez na história do pensamento etnológico, um esforço foi feito para transcender a observação empírica e atingir realidades mais profundas" (: XXXIII). Realidades, no entanto, que Mauss não pôde ele próprio acessar. Não foi a primeira vez nem será a última que Mauss é acusado de não perseguir até o fim os caminhos de uma certa pesquisa ou de não atingir um determinado objetivo.

Trata-se de um problema teórico. No caminho em direção ao estruturalismo, o que deteve Mauss? O que o impediu de atingir as "imensas possibilidades" que o esperavam além da margem que ele não soube atravessar? Uma ilusão, no limite, provocada pela "observação empírica" que não "fornece a troca, mas somente (...) três obrigações" (: XXXVIII). Em Lévi-Strauss a heterogeneidade é só uma aparência. A realidade verdadeiramente real é sintética e homogênea. Se Mauss não atingiu a homogeneidade, e portanto os universais gerais, foi por falta de procedimentos científicos; se não atingiu a realidade mais profunda da troca foi porque se manteve no nível das superfícies conscientes que the forneciam apenas as obrigações de dar, receber e retribuir. Mas, se o social somente é real se tomado em sistema, como conjugar estes três elementos dissociados desde o início? Através, diz Lévi-Strauss, de uma explicação secundária. Mauss deu crédito a uma explicação secundária, 
e portanto consciente, a uma explicação racionalizada chamada hau. No entanto a troca não é formada por elementos dissociados aguardando uma síntese a posteriori. Ela é sintética a priori. Síntese formulada não no nível das consciências, mas no inconsciente. A reciprocidade está fundada no inconsciente.

É possível que a compreensão mais adequada deste enunciado seja encontrada em uma outra obra, As estruturas elementares do parentesco, publicada em 1949. A questão de base é, ali, assim formulada: de que forma a reciprocidade, dando lugar à troca, pode ter ligação com o inconsciente estrutural (Simonis, 1979)? A troca é uma totalidade e Lévi-Strauss pretende encontrar a realidade subjacente que é a totalidade da troca. Pode-se dizer que a reciprocidade de base é a exogamia, ela própria uma condição de possibilidade, uma garantia para o estabelecimento de uma troca. A exogamia está para além da proibição do incesto, ou seja, na cultura; e para aquém, quer dizer, na natureza. $\mathrm{Na}$ cultura ela é uma troca e sobretudo uma aliança. $\mathrm{Na}$ natureza, age em termos de inconsciente estrutural (: 28). A proibição do incesto é ela própria uma síntese; um fenômeno de natureza e de cultura; é uma "regra universal"', "lugar preciso da passagem da natureza à cultura" (: 30).

Qual a natureza dessa regra universal? Para Simonis, ao aprofundar esta natureza, Lévi-Strauss penetra no problema da reciprocidade. Se a proibição do incesto é da natureza, dela só se poderia apreender os efeitos: a diversidade das formas de proibição (idem; Lévi-Strauss, 1971: 34). Estas últimas dizem menos respeito à consangüinidade do que ao fenômeno social. Trata-se menos de biologia do que de classificação pois, na reprodução humana, a natureza diz que as pessoas devem ter pais e mães, mas silencia sobre o fato de quem serão os pais e as mães das pessoas. E lá, onde a natureza se cala, a cultura é loquaz. A "proibição do incesto exprime a passagem do fato natural da consangüinidade ao fato cultural da aliança" (Lévi-Strauss, 1971: 35). Mas a aliança é imposta pela natureza que, contudo, não a determina. Ela é um espaço vazio preenchido pela cultura. 
Ao efetuar este tipo de intervenção, a proibição do incesto não esgota o seu conteúdo na proibição. Ela garante e funda uma troca. "Como a exogamia, a proibição do incesto é uma regra de reciprocidade: pois renuncio minha filha ou minha irmã à condição que meu vizinho às suas também renuncie" (Lévi-Strauss, 1971[1966]: 72). Não se trata de um "meio" para permitir a troca já que "contém em si (...) a Cultura, a promessa de que a vida social que instaura é um sistema de trocas" (: 37). A troca ou a reciprocidade, para Simonis, é o que explica a proibição do incesto. Existe uma estruturação natural inconsciente da qual a proibição do incesto é apenas a "testemunha obrigatória" no nível cultural. E é essa mesma estruturação inconsciente a responsável pela emergência do pensamento simbólico e da proibição do incesto.

De que modo a troca pode se integrar ao inconsciente estrutural, às estruturas fundamentais do inconsciente humano? De que modo a passagem do estado de natureza ao estado de cultura se relaciona a essas estruturas? Pela "aptidão" humana para pensar relações biológicas sob a forma de sistemas de oposição. Eis aí a importância das sociedades dualistas no que concerne à integração acima referida. A troca apenas resulta dos pares de oposição: é ela que explica e garante o mundo da reciprocidade. Mas como explicar a troca? A base das instituições matrimoniais são as estruturas formais, ou seja, os grupos de oposições binárias. Quer dizer, são também a base da interdição do incesto e da Cultura que esta funda. Não é a interdição do incesto que está na base. Ela não é a causa, é apenas a condição ou o processo da passagem:

A proibição do incesto é o processo pelo qual a naturez̧a se ultrapassa a si mesma; ela acende a faísca sob a ação da qual uma estrutura de um novo tipo, e mais complexa, se forma e se superpõe, integrando-a, às estruturas da vida psíquica. (: 29)

É o estrutural, o inconsciente que explica a troca. É ele o sustentáculo da proibição do incesto, e esta é a "regra do dom por excelência". Ela obriga dar a filha ou a irmã a um outro grupo; "a proibição do incesto é o sinal da inelutabilidade da troca” (Simonis, 1979: 52). 
Revista de Antropologia, São Paulo, USP, 2001, v. 44 nº 1.

Se a interdição do incesto explica a troca, ela própria é explicada pela "aptidão" das estruturas mentais em pensar as relações biológicas como sistemas de oposição. Ora, a explicação da interdição do incesto enquanto fruto das oposições binárias não é exatamente uma novidade. Durkheim já havia explicado assim. O sistema de classificação primitivo do qual deriva a concepção totêmica do mundo é originada num sistema dual. Mas a binaridade de Lévi-Strauss não é gerada na ordem da sociedade. Ela é um universal. As formas sociais não determinam a formação de categorias do pensamento. Rejeitado o determinismo social, a classificação dos grupos e da natureza derivam de um modo de categorização com o qual os seres humanos operam. Assim se supera também a necessidade do hau: não uma soma de três elementos, cujo resultado seriam os sistemas de prestação totais, mas uma síntese a priori operada por um inconsciente estrutural, por um sistema de oposições binárias.

As apresentações do "Ensaio sobre o dom" são muito diversas, assim como as pretensas críticas à teoria do dom, por exemplo a de Alvin Gouldner (1960) ou de Jonathan Parry (1984). Mas, dentre todas as outras, escolho a de Claude Lefort (1979) por se tratar de uma tentativa muito original, mantendo-se, no fim, presa a todas as tendências dos demais textos: dom como fundador da sociedade, como produtor de homeostase social, como fruto do reconhecimento e da dialética.

Lefort qualifica o "Ensaio" como um texto "sobre os fundamentos da sociedade" (:23), uma descrição de como os homens puderam estabelecer-se coletivamente. Através do intercâmbio de dons: uma forma de circulação na qual estão empenhados bens tangíveis e, sobretudo, intangíveis. De um modo que sempre é preciso retribuir com usura e, como notará mais tarde Pierre Bourdieu, "a prazo". O problema do tempo (Bourdieu, 1996) é importante em Lefort em virtude de um elemento introduzido por ele e não negligenciado por Bruno Karsenti: a liberdade. Como afirma este último, em relação ao determinismo social criado por Durkheim, as teorias de Mauss introduzem um toque de liberdade. O dom é ao mesmo tempo voluntário 
e absolutamente obrigatório. A liberdade, ainda que seja aparente, como quer Lefort, supõe alguns outros quesitos: o crédito, a confiança do homem no homem.

Mas a problematização de Lefort parece ser mais profunda e mais geral: “Qual é o sentido da troca por meio de dons?” (1979: 25). Colocada ao lado de Lévi-Strauss, desqualifica a questão de Mauss (o que faz um dom ser devolvido?). Este problema mal colocado não apenas arrisca dar crédito a uma explicação nativa, mas deixa de justificar o essencial: o que explica a obrigação de dar? A resposta de Mauss parece insuficiente a Lefort porque não torna necessário o estabelecimento de um laço, já que, tendo o donatário direito de propriedade sobre o que pertence ao doador, nada foi dado e nada foi recebido. Ao contrário, um intercâmbio suporia seres separados: "se dou ao outro é porque ponho o outro como outro e estas coisas como minhas para o outro" (Lefort, 1979: 26).

Se Lefort refuta Mauss não é para chegar a Lévi-Strauss. Em lugar do sistema e da regra, o que propõe ele?

Em Lefort não existe um "fato" da obrigação, seja ela metafísica ou matemática (: 30). Um sintoma de que a obrigação não existe como fato apareceria no próprio Mauss, quando este afirma a obrigatoriedade das prestações sob pena de guerra. Ou seja, emprestando-se de Sahlins a expressão, a Razão pode ser traída. Donde as trocas não podem ser voluntárias exatamente porque elas não são dadas ou determinadas. A reciprocidade é um "ato". A troca é "um ato que separa os homens e os coloca frente a frente" (: 31). Assim, o exemplo privilegiado volta a ser o do potlatch. Onde mais, como dizia Karsenti, poder-se-ia encontrar um "ato" mais antitético e complementar do que no potlatch? E, de que modo, no potlatch, a honra é "constitutiva da subjetividade"? É no desafio que o homem se vê ameaçado na idéia que faz de si mesmo. E na dialética do senhor e do escravo, o processo de subjetivação, a idéia que se tem de si mesmo, deriva de um julgamento tortuoso cuja lógica será vista a seguir. Assim se pode dizer que é a partir do outro, do reconhecimento, que é construída a idéia que se tem de si mesmo. É 
claro, Lefort não está inventando tudo isso. Ele não viu a dialética do escravo apenas por ser coetâneo, ou quase, dos alunos de Alexandre Kojève. Estas mesmas afirmações, e ele o mostra suficientemente bem em seu texto, estão no próprio "Ensaio".

Um dos mais interessantes complementos ao "Ensaio" é o de Marshall Sahlins. "A filosofia política do Ensaio sobre o dom" tenta estabelecer um paralelo entre as obras de Hobbes e de Mauss. Sahlins encontrou em Mauss um equivalente para o Estado de natureza de Hobbes: o estado anterior ao dom. O conteúdo, o objetivo e a intenção do artigo aparecem já em suas primeiras linhas:

À guerra de cada homem contra cada homem Mauss substitui a troca de todos entre todos. O hau, espírito do doador no dom, não seria a razão última da reciprocidade, mas apenas uma proposição particular que se inscreve no contexto de uma concepção histórica dada (...) nova versão do diálogo entre caos e contrato. (...) $\mathrm{O}$ acordo primeiro foi consentido não à autoridade, nem mesmo à unidade. $\mathrm{O}$ análogo primitivo do contrato social não é o Estado, é o dom. (Sahlins, 1976b: 221)

Os homens, Sahlins faz Mauss dizer, estariam encurralados entre duas águas: ou trocam ou guerreiam entre si. A circulação de dons, as prestações totais seriam o meio através do qual a paz se estabeleceria. Dar, receber e retribuir aparecem como uma forma de recusar a guerra. "O dom é a maneira primitiva de obter esta paz que na sociedade civil é assegurada pelo Estado" (: 221). Tanto em Mauss quanto em Hobbes, a guerra é uma realidade subjacente à realidade humana. Em ambos os casos um meio de esconjurá-la foi encontrado: seja através do Estado, seja através do dom. Ambos, para Sahlins, obedecem ao princípio da Razão.

O Estado de natureza de Hobbes, diz Sahlins, é também uma estrutura política. A guerra não é somente uma inclinação, é um direito de lançar mão à violência. Há instinto de competição e legitimidade da confrontação (Sahlins, 1976b: 224). Então, o Estado de natureza já é uma sociedade; sociedade sem soberano. Sociedade em que o direito de batalha é detido por todos e por cada um. 
Do mesmo modo, sempre segundo Sahlins, Mauss funda a teoria geral do dom sobre a especulação de um estado de natureza social não verificável, porque contrariado a todo momento pela lógica do dom. A base da natureza social são grupos postos lado a lado, sempre inclinados ao combate. A razão da exigência da reciprocidade é a evitação da guerra. Não dar equivale recusar aliança, ou seja, equivale declarar guerra. O dom mesmo, diz Sahlins, é a Razão.

O paralelismo Hobbes/Mauss situa-se na conclusão segundo a qual cada indivíduo submete-se a uma ordem e a uma exigência gerais ou coletivas. Sahlins justapõe a troca-dom à segunda lei da natureza de Hobbes:

Este consente, quando outros consentem, isto na medida em que julga a coisa necessária à Paz e a sua própria defesa, a depor seu direito sobre todas as coisas e a contentar-se de tanta liberdade em relação ao outro quando ele concorda com o outro em relação a ele. (apud Sahlins, 1976b: 231)

E ainda mais na quarta lei, a da gratidão:

a gratidão procede de uma graça antecedente (...) de um livre dom antecedente, e esta é a quarta Lei da Natureza (...) que aquele, que recebe Benefícios de um outro por simples bondade, faça de modo que este que deu não tenha ocasião de razoavelmente arrepender-se de seu bem-querer. (idem)

Existe uma correspondência entre os dois autores fundada na apreciação similar da reciprocidade enquanto modo primitivo de paz. Não obstante, a identidade Hobbes/Mauss termina aqui, embora tanto Mauss quanto Hobbes admitam a insuficiência da Razão como garantia do contrato - já que as leis da natureza são contrárias às paixões naturais humanas ${ }^{4}$. Diante da necessidade de lavar sua honra, os pactos não são mais do que palavras lançadas ao vento, sem força alguma para ligar os homens. A lei natural é fundada em última instância num poder artificial e a Razão tem como única caução a autoridade.

Embora igualmente duvide da capacidade de a Razão garantir o pacto, o contratualismo ${ }^{5}$ maussiano desenvolvido por Sahlins, contudo, não apresenta como garantia do contrato a constituição de uma 
autoridade pública transcendente à sociedade. A garantia do "contrato social à moda primitiva" não se apresenta artificial como no contrato do Estado, é irracional como no hau. "A troca é o triunfo da razão, mas há que haver o espírito encarnado do doador para que o dom seja pago em retorno" (Lévi-Strauss, 1976b: 232).

As teorias de Sahlins a respeito da reciprocidade não se limitam a essa identificação entre Hobbes e Mauss. Em 1965, aparece "A sociologia da troca primitiva" no qual são arroladas três formas de reciprocidade: a generalizada, a equilibrada e a negativa. Esta cartografia da reciprocidade obedece a um esquema concêntrico: no ponto mais central da sociedade - a casa - a forma é a da reciprocidade generalizada; dali até a periferia - passando pelos setores da linhagem, da aldeia, da tribo até o intertribal - a reciprocidade é, relativamente aos três primeiros, equilibrada e; por fim, negativa. Se a moralidade entra como um termo a ser contado no esquema da reciprocidade, também ela "tende a se organizar no nível setorial", pois a "reciprocidade e a moralidade são estruturadas por setores - a estrutura é a dos agrupamentos tribais organizados em função do parentesco" (: 254-6).

Já em 1965, Sahlins preludia o modelo proposto por ele três anos depois: a reciprocidade como meio para a paz.

Os fluxos de bens caucionam ou instauram as relações sociais e é assim que os povos primitivos transcendem o caos inicial postulado por Hobbes (...) assegurar a paz não é um acontecimento esporádico (...) mas uma processo contínuo que se persegue no seio mesmo da sociedade. (: 239)

Este entendimento da reciprocidade compreende uma lista significativa de autores, todos eles de uma forma ou de outra ligados ao "Ensaio sobre o dom". Mais recentemente, Chris Gregory (1982) objetiva uma distinção cirúrgica entre modos de circulação correspondentes a dois tipos de sociedades:

Em uma sociedade de classes, os objetos de troca tendem a assumir a forma alienada de uma mercadoria e, como conseqüência, a reprodução em geral assume a forma particular de reprodução de mercadoria. Em uma sociedade 
de clã os objetos de troca tendem a assumir a forma não alienada de um dom; a reprodução assume a forma particular de reprodução de dom. (: 41)

Não apenas existem dois modos de produção, circulação, consumo e reprodução, como existem tipos de sociedades que condicionam os modos segundo os quais coisas e pessoas circulam, são produzidas, consumidas e reproduzidas. Sociedade de classe, sociedade de clã. Existiria um corpo social, de tipo clãnico, que, ao encontrar-se com coisas, terra e trabalho, produz neles o efeito de uma forma-dom e, ao contrário, um outro corpo social, de classes, que, ao encontrar-se com estas mesmas coisas, produz mercadoria.

Uma troca, diz Gregory, é uma transação que envolve duas partes e dois objetos. A distinção entre uma troca-dom e uma troca-mercadoria é que a primeira estabelece uma relação entre pessoas, enquanto a segunda estabelece uma relação entre as coisas. Um outro traço da troca-dom é a impossibilidade de independência recíproca das partes. Pessoas em uma sociedade de clãs estão sempre em dependência recíproca que deve ser medida, como em Sahlins, segundo a distância do parentesco. A motivação das transações também é oposta nos dois casos. No caso do dom, a motivação é "oposta à do capitalista" (1982: 51). É preciso que se maximize o que sai para que se maximize também o número dos seus seguidores ou devedores. Segundo Gregory, na linha de Mauss e muitos outros, quem dá assume uma posição de superioridade, pois a relação de dom é a fundadora de uma relação social ${ }^{6}$. O desejo de criar em torno de si um grupo de devedores provoca alternância de posições ou, como diz, Gregory, "desequilíbrio alternado". Como na queda livre que sucede a ascensão, o corpo móvel pára por um momento, nas relações de dom e contra-dom, a dívida se fecha no momento da alternância do seu sentido. Este é o momento da estabilidade. Há uma diferença de forma entre doação de dons balanceada e incrementada, diz Gregory. Na forma que incrementa o dom a cada contra-dom, "a seqüência combina dois dons: uma parte do dom devolvido cancela a dívida original, a outra parte cria uma nova dívida" 
Revista de Antropologia, São Paulo, USP, 2001, v. 44 nº 1.

com o sentido invertido (1982: 54). Embora a argumentação de Gregory pareça privilegiar o desequilíbrio, persiste aí uma velocidade zero que é o momento da inversão no sentido da dívida, a idéia de que a relação seja sempre modulada pelo sentido da circulação dos dons.

\section{A dialética - reconhecimento e negação}

Estas três abordagens da reciprocidade - a de Lévi-Strauss, a de Sahlins e a de Gregory - em que pesem todas as suas diferenças e as nuances do livro deste último, têm em comum, entre elas e muitas outras, a compreensão da troca, da reciprocidade, da circulação de bens, como a fundação da sociedade, como uma função que é a do equilíbrio e da estabilidade social. Mas o problema das identificações entre teorias da reciprocidade não se esgota aqui.

Pierre Bourdieu pode ser considerado um dos grandes subescritores de uma teoria da reciprocidade como dialética e reconhecimento.

Quando se trata de caracterizar a troca por dom em função do elemento de rivalidade que se exprime nele, é menos em Hobbes que se pensa do que em Hegel, e mais precisamente no Hegel lido por Kojève no quadro do curso que consagra à Fenomenologia do Espirito, na França, no começo dos anos 30. Principalmente tendo como eixo a "dialética do senhor e do escravo" (...) "uma luta de morte em vista do reconhecimento". (Karsenti, 1994: 33)

A precisão da observação de Karsenti pode ser ainda melhorada já que não se pode pretender que esta compreensão se deva somente ao fato de apenas os intelectuais franceses desta época terem sido, por assim dizer, forçados a ver no potlatch a representação palpável dessa luta. Os exemplos oferecidos por Karsenti são limitados, tendo em vista as dimensões da lista possível: Bataille, Leiris, Caillois. Difícil, talvez, seria encontrar algum antropólogo que tenha fugido a esta perspectiva. É preciso lembrar que o hegelianismo não se esgota em um curso, qualquer que seja o seu brilho, seja qual for a influência futura das obras de seus alunos. 
$\mathrm{O}$ argumento de Bourdieu pode ser resumido a partir da seguinte citação:

Numa economia que se define na recusa em reconhecer a verdade "objetiva" das práticas "econômicas", quer dizer, a lei do "lucro nu" e do "cálculo egoísta", o próprio capital "econômico" só pode agir se chega a se fazer reconhecer ao preço de uma reconversão própria a tornar irreconhecível o verdadeiro princípio de sua eficácia: o capital simbólico é o capital negado, reconhecido como legítimo (...) que constitui, com o capital religioso, a única forma possivel de acumulação quando o capital econômico não é reconhecido. (1994: 200-1)

Existe uma "tensão" para a acumulação do capital simbólico que não corresponde a uma intenção consciente. Ela não é individual, é "uma disposição do babitus que é a generosidade, e que tende, sem intenção explícita e expressa, à conservação ou ao aumento do capital simbólico" (Bourdieu, 1996: 9). O comportamento generoso não é, portanto, deliberado, ele é entendido pelos que são "dotados de disposições ajustadas à lógica da economia dos bens simbólicos (...) como a única coisa a fazer" (idem). Embora não seja calculista, a economia do dom, na recusa ao capital econômico, visa a acumulação de um capital que pode ser traduzido em riquezas de aliados, serviços, credores, enfim, do reconhecimento. Nesse sentido o capital simbólico é um crédito. Não existe acumulação de um tal capital se não houver um outro que olhe e avalie a ação generosa, ou corajosa. Assim, o dom só é possível ali onde são esperadas, recompensadas e reconhecidas as ações generosas. O homem honrado não se constitui como tal sem que haja reconhecimento. Pode-se dizer que toda a literatura sobre a honra está contaminada por essa idéia. Um rio do qual Mauss é também um tributário: "Entre chefes e vassalos, entre vassalos e tenentes, por esses dons, é a hierarquia que se estabelece. Dar é manifestar sua superioridade, ser mais, mais alto, magister' (1993: 269).

A lógica da honra Cabília é regida pelo princípio do reconhecimento. Para que haja desafio, é preciso haver reconhecimento da igualdade das partes desafiante e desafiada, porque desafio e ofensa conferem honra, porque quem desafia um homem incapaz de responder desonra-se a si 
mesmo, porque só o desafio vindo de um igual em honra merece resposta. Os três corolários apresentados por Bourdieu, de resto ponto a ponto transponíveis para uma lógica do dom, não funcionam sem o princípio do reconhecimento, da apreciação e da avaliação de um outro, seja ele coletivo ou individual.

Mas, no limite, quem escapa de fato deste problema do reconhecimento, da dialética do senhor e do escravo? Veja-se o caso de Pierre Clastres. Os Hochero, os Kaanoklé, os Niadagaguadi, por que se exporiam eles à morte? Para Clastres é em função do reconhecimento da sociedade. Reconhecimento este que, se retirado, privaria o guerreiro da própria vida social. E se a memória dos Apaches, dos Guaicurus, dos Chulupis é curta, há de reativá-la com um novo desafio cada vez mais mortal, reativando assim o reconhecimento.

\section{O ensaio de Nietzsche}

Nietzsche não teve acesso ao enorme manancial de dados etnográficos aos quais Mauss fôra exposto, entre outras ocasiões, enquanto resenhista do Année Sociologique. Contudo, as informações a respeito das sociedades primitivas não lhe eram totalmente estranhas. Sua estadia na Basiléia o pôs em contato com o jurista-antropólogo suíço Jean-Jacques Bachofen. É bem verdade que os dados fornecidos por Bachofen em sua íntima convivência eram predominantemente referentes à antigüidade clássica e não aos povos primitivos. No entanto, foi através da obra e da amizade de Bachofen que Nietzsche pôde constituir a sua idéia de pré-história (Andler, 1979, vol. I: 420 e 423; vol. III: 308). Os dados propriamente referentes aos povos primitivos, à pré-história européia e ao direito comparado vieram de diversos autores ${ }^{7}$. Mas é possível que os dados mais fundamentais para a construção das teorias expostas na Genealogia da moral tenham sido retirados da biologia de Wilhelm Roux e W. Rolph ${ }^{8}$.

Em comum o "Ensaio" e a Genealogia têm, se se exclui o tema dos povos primitivos, as fontes. Direitos antigos: código de Manu, direito 
romano antigo, direito germânico, Grécia; o uso, com um peso em cada caso, é verdade, da filologia; os temas tocados, ao menos na "segunda dissertação", são extremamente próximos, de tal modo que em certas passagens as conclusões são quase equivalentes. E, no entanto, os resultados são bastante diferentes. Como poderiam explicar-se as distâncias entre uma e outra obra? O momento histórico? As formações e influências sofridas pelos dois autores? As nacionalidades e as religiões? As biografias, enfim? Seguramente tudo isso. Acrescente-se a isso o que se poderia chamar de objetivo ou material de base.

Qual é, então, o objetivo, como funciona, para que serve a Genealogia da moral? A resposta mais incisiva vem da boca de um médico:

A Genealogia da moral não teria outro objetivo aparente que o de apoiar sobre a filologia o combate que ele [Nietzsche] sustentou em nome da vida contra o dogma negador que procura diminuí-la. A leitura de Spencer tinhalhe revelado o antagonismo fundamental de seu pensamento científico com o pensamento dos que se apropriaram da ciência para dar à moral a base utilitária que tende a mantê-la. (Faure, 1964:162)

A obra já é fruto de um combate e é da mesma forma a apresentação de um grande combate: o das forças reativas contra as forças ativas e vice-versa. Não se trata, como em Mauss, de descobrir e apresentar nem um fato típico nem os fundamentos da sociedade. Trata-se de descrever calma e engenhosamente, como disse Charles Andler (1979, vol. II: 570), a vitória da reatividade sobre a atividade, da negação sobre a afirmação. Este combate é o fundamento desse estranho materialismo nietzscheano.

Assim como Mauss, Nietzsche aproximou-se de uma tradição que tentou ligar as sociedades humanas às sociedades animais, as culturas ao organismo. Assim como fez Durkheim, o fez também Espinas. Somente, no caso de Nietzsche, a correlação não é de comparação, nem de analogia, caminho seguido pela tradição spenceriana. O indivíduo já é uma coletividade, o organismo é um teatro de batalha, ou nem sequer isso, porque não há teatro, não há “campo de batalha”, só há a batalha (Deleuze, 1998: 45). O sujeito é uma multiplicidade. Os 
Revista de Antropologia, São Paulo, USP, 2001, v. 44 nº 1.

organismos são já vidas e consciências coloniais e toda sociedade é um vivo (Andler, 1979, vol. III: 317).

A questão de base é, então, a do combate. Um combate que não é propriamente humano, mas que remonta à matéria mesma. Os ensinamentos que recolhe dos biólogos citados parecem lhe dizer isso: na natureza, bem como nas sociedades humanas, existem forças que concorrem na formação e na transformação dos organismos e das formações sociais. Há ao menos dois tipos de forças, as superiores, de comando, ou forças ativas e as inferiores que devem ser acionadas, devem obedecer, devem ser uma função, as forças reativas:

Toda força está em relação com outras forças, seja para obedecer, seja para comandar. O que define um corpo é a relação entre as forças dominantes e as forças dominadas. Toda relação de forças constitui um corpo: químico, biológico, social, político. (Deleuze, 1998: 45)

O problema é então o da tipologia das forças e dos corpos; logo, dos homens também. Existe um tipo que é o ativo e um tipo que é o reativo. A cada um corresponde uma descrição das relações de forças que o compõem. O tipo ativo é aquele no qual as forças ativas são capazes de fazer reagirem, obedecerem, as forças reativas. Estas são ativadas por aquelas. No tipo reativo, um dano nas forças ativas as impede de ativar as forças reativas que, desse modo, não reagem mais. Eis aí a origem do ressentimento e da má consciência ${ }^{9}$.

De que modo todo este processo se dá no homem, este é o tema da Genealogia. Segundo Nietzsche, antecipando-se aos enunciados da biologia e da etologia do século XX, aparece sobre a Terra um "animal necessariamente esquecido" para o qual é tarefa da Cultura fazer uma memória (1912, vol. II: 1). Fazer no homem uma memória, este "trabalho do homem sobre o homem", é organizar nele as forças que o definem. É fazer as forças ativas agirem sobre as forças que devem reagir: adestramento. Mas é também produzir um tipo especial, o animal capaz de prometer (idem; Deleuze, 1998: 152 e ss.), o animal autônomo e supramoral. 
É este animal que vai criar para si uma consciência voltada para fora, para o momento presente e, doravante, para o futuro. Pois a nova memória produzida pela Cultura é uma memória do futuro e não uma memória das marcas. Estas não devem povoar a consciência, sob pena de desviá-la de sua possibilidade de reagir ao momento presente. E o que lhe vai dizer esta consciência? Que ele, "mestre do livre-arbítrio", animal capaz de prometer, é superior, é nobre, é forte e capaz de comando. Ele é bom (Nietzsche, 1912, vol. I e II). Não há comparação das consciências: ele julga a partir de si constituindo para si mesmo uma tábua de valores, uma moral que é a dos senhores. E se ele julga a partir de si, onde está o reconhecimento?

Acompanha essa moral todo um ethos que se contrapõe ponto a ponto à moral dos escravos. Mas não se poderia confundir um ethos com "atos" nem com "ações". Por que não se pode fazer genealogia da moral fundada em atos que seriam reconhecidos como bons e maus? Não é sobre atos que se valora, é sobre homens. O que fazem os bons, todo ato seu - o seu modo de ser - é "bom". Tudo aquilo que é o contrário dele é "mau". Uma avaliação, portanto, a partir de si próprio que não leva em conta nenhum reconhecimento.

A outra moral, a moral do escravo, é muito mais complicada, como, de resto, compete aos seres mais complexos e mais "interessantes" que são. Tudo o que "eles são" é mau e, por conseqüência, tudo o que é o contrário do que eles são, ou seja, eu, é bom. É uma avaliação que tem como ponto de partida o outro e que não existe sem um outro.

O ethos do homem superior é o da acumulação para o gasto (Bataille 1975). Como no materialismo nietzscheano toda sociedade humana tem suas raízes nos instintos da vida animal e da vida como um todo, o modo afirmativo de ser está em adequação com as potências da vida. E a primeira relação entre vivos é a da predação. Em Nietzsche existe "uma moral dos senhores desde a primeira sociedade animal" (Andler, 1979, vol. II: 535). Assim, nada na vida animal ou social pode-se explicar, ao contrário do que ocorre na obra de Bourdieu, pelo instinto de conservação: 
O instinto de acumular que leva os povos primitivos a reservar (...) valores de troca (...) não se poderia explicar só pelo fato do instinto de conservação. Adquirir, enriquecer, já é o engrandecimento de si, sem dúvida; mas é ainda defesa, precaução, e, no fim das contas, medo. Ele só pode nascer das civilizações mercantis (...). Nem a abnegação, nem a necessidade de dominar acumulam avaras reservas. Elas lançam ao vento seus tesouros. (Andler, 1979: 537)

O instinto dominante não pode se explicar pela acumulação e pela conservação porque ambas estão fincadas na moral do tipo dominado, que prevê o outro para que a acumulação seja, uma vez ligada a seu proprietário, objeto de reconhecimento. Mesmo em Mauss há um certa ambigüidade no que toca a acumulação. $O$ chefe melanésio prefere ser "o primeiro, o mais belo, o mais feliz, o mais forte, o mais rico, eis aí o que se procura", tendo ele um modo especial de obter tudo isso: "confirma seu mana redistribuindo a seus vassalos, parentes, o que ele acaba de receber (...) Neste caso a riqueza é, sob todos os pontos de vista, tanto um meio de prestígio quanto uma coisa de utilidade" (1993: 270). Utilidade, já que o objetivo, enfim, é o reconhecimento de outro e não uma afirmação de si. Mas uma leitura não hegeliana de Mauss revela, linhas adiante, uma frase que cancela o que foi dito:

Entesoura-se, mas para gastar, para “obrigar” (...). Dá-se com usura, mas é para humilhar o primeiro doador ou troquista e não somente para recompensá-lo pela perda que lhe causa um consumo diferido. Há interesse, mas este interesse não é análogo àquele que, diz-se, nos guia. (: 271)

Aqui já não importa a avaliação externa, mas a sua própria. O desejo é o desejo de obrigar, um desejo de domínio sobre o outro. O duelo perde seus ares de confrontação.

\section{O problema do tempo e a dívida aberta}

Não há, na "segunda dissertação", afirmação que a relação credor/ devedor funda alguma coisa. Ser a primeira relação do homem com o homem não implica ser fundadora da sociedade. A relação dívida/ 
crédito só é possível como fruto de um processo cujo ponto inicial, no caso de se procurar ardentemente um, é a criação de uma força contrária à potência ativa do esquecimento. Porque há alguma coisa que possibilita a própria dívida, o próprio crédito e a troca. Do mesmo modo, não existe teoria do contrato na Genealogia. Não há Razão que possa dispensar direitos e egoísmos. O contratualismo é retirado do caminho com um delicado golpe de espanador: "àquele que sabe comandar, àquele que a natureza fez um 'senhor', àquele que se mostra poderoso em sua obra e em seu gesto - que importam a este os tratados!” (Nietzsche, 1912, vol. II: 17). Se a troca ou o dom não fundam a sociedade, o que a funda? Se não é um contrato, só pode ser uma imposição, um ato de violência. Se o contrato é uma evolução, a concorrência das forças provoca transformação não evolutiva, fatalista e circunstancialista. A rejeição do contrato pode ser explicada pelo fato de nem a reciprocidade, nem a troca, nem o dom serem o fundamento da sociedade, pois todas estas coisas já supõem uma série de outras.

A esse respeito, Gilles Deleuze e Felix Guattari, ao refletirem sobre o problema da rejeição da tendência troquista e a assimilação da noção de dívida em Nietzsche, afirmam que:

o grande livro da etnologia moderna é menos o "Ensaio sobre o dom" do que a Genealogia da moral, ou pelo menos deveria ser. Pois a Genealogia, a segunda dissertação, é uma tentativa e um êxito sem igual para interpretar a economia primitiva em termos de dívida, da relação credor-devedor, eliminando toda concepção de troca. (1994: 224)

E também:

A questão que Mauss havia deixado não concluída: dívida é primeira em relação à troca ou ela só é um modo de troca, um meio ao serviço da troca? Lévi-Strauss pareceu concluí-la com uma resposta categórica: a dívida só é uma superestrutura. (:219)

Em que pese a impressão inicial, no lugar da troca não entra a dívida, que não é fundadora mas, parte de um processo à qual está submetida. Este processo é o da mnemotecnia, a "inscrição territorial 
primitiva", o "socius inscritor". É a inscrição a fonte de todas as possíveis distinções que garantem, exigem e negam todos os engajamentos. É ela que torna o homem um animal "apreciável, regular, necessário" (Nietzsche, 1912, vol. II: 1). Ora, apenas sob condições em que uma memória esteja em processo de constituição ou esteja constituída é possível haver credores e devedores, pois a memória voltada para o futuro possibilita a própria dívida. É bem verdade que a dívida e o crédito são indissociáveis e de certo modo também constituintes desta nova "memória das palavras" (: 169 e 225). Mas certamente não se pode criar dívida onde se esquece a palavra empenhada no mesmo instante em que se a pronuncia. Para Nietzsche, Deleuze e Guattari é o sistema gráfico, meio através do qual se faz ao homem uma memória, que garante a codificação dos fluxos decodificados do desejo sobrepondo a uma memória "noturna", a uma "filiação intensiva", uma memória das palavras e dos nomes, um sistema de alianças e uma filiação extensa $(: 182-3)^{10}$.

Segundo $O$ anti-Édipo, a produção de uma memória nova insere o desejo na produção e a produção no desejo (: 170); a "produção desejante" está ligada assim à produção e à reprodução sociais (: 163). Isto se dá através do sistema da crueldade:

A máquina territorial primitiva codifica os fluxos, investe os órgãos, marca os corpos (...). A essência do socius gravador, inscritor, enquanto se atribui as forças produtivas e distribui os agentes de produção, reside nisto - tatuar, excisar, incisar, recortar, escarificar, mutilar, cernir, iniciar. (: 169)

Isto é, codificar os fluxos do desejo, o que implica a separação dos fluxos, os cortes, a repartição das partes (: 166). Isto faz da sociedade, segundo os autores, antes um meio de marcação que um meio de troca.

A codificação de todos os fluxos implica o recalcamento da memória das filiações intensivas e produz um sistema extensivo que é uma memória das alianças (Nietzsche, 1912, vol. II: 182). Produz também uma extensão do próprio tempo. Porque, como diz Nietzsche, uma promessa é a enunciação de uma vontade cuja descarga, o cumprimento 
do ato, só se dará no futuro. A promessa, o engajamento, o laço, o nexum, temas de resto tão presentes no "Ensaio", precisam de um intervalo, precisam do prazo. Nietzsche não foi o único a reparar nisso. Mas o problema do tempo não tem sido enfocado em si mesmo. Se se procurou no dom e na reciprocidade o fundamento da sociedade, esqueceu-se de dizer que não é na dissolução da dívida e do crédito criados pelo dom que a sociedade se estabelece.

O sistema da crueldade transforma "homens e seus órgãos em engrenagens da máquina social” (Deleuze \& Guattari, 1994: 170). E é da natureza desta máquina "declinar aliança e filiação" (: 171). No processo de recalcamento da memória intensiva, a aliança desempenha o papel fundamental de constituinte do processo mnemônico:

como lhe fazer uma memória nova, uma memória coletiva que seja a das palavras e das alianças, que decline as alianças com as filiações estendidas (...)? A resposta é simples, é a dívida, são os blocos abertos de dívidas, móveis e finitos (: 225)

Segundo Deleuze e Guattari, o problema central de uma sociedade não é o da circulação nem o da troca. Para eles a dívida não aparece como uma superestrutura que recobre uma realidade inconsciente que subjaz a ela. Em $O$ anti-Édipo, a troca e a equivalência são coisas que, nas sociedades primitivas, devem ser esconjuradas

para que não se desenvolva nenhum valor correspondente como valor de troca que introduziria o pesadelo de uma economia de mercado (...) a economia primitiva procede por barganha antes que por fixação de um equivalente. (:220)

Embora talvez possa não ser reduzida a ela, a tendência "a postular um tipo de equilíbrio de preço, de equivalência ou de igualdade primeiras nos princípios" é debitada à "concepção estrutural troquista" (Deleuze \& Guattari, 1994: 220). O ponto de partida é o equilíbrio do sistema. Seus desequilíbrios, as desigualdades, são explicadas como conseqüências, patológicas ou não, da aplicação dos sistemas. Sobre isso, os autores perguntam: 
trata-se de saber se o desequilíbrio é patológico e de conseqüência, como crê Lévi-Strauss, ou se é funcional e de princípio, como o pensa Leach. A instabilidade é derivada em relação a um ideal de troca, ou antes já dada nos pressupostos, compreendida nas heterogeneidades dos termos que compõem as prestações e contraprestações (: 221)

Se existe um princípio de reciprocidade, como queria Malinowski (apud Gouldner, 1960: 169), criador de uma dependência mútua, ela não se dá, no entanto, no seio de "arranjos equivalentes de serviços recíprocos" (idem). Como diz o próprio Gouldner, confirmando até aqui Mauss, o "recebedor está (...) obrigado ao doador, e assim continua até pagá-lo" (: 174). Quer dizer, o endividamento aparece entre o tempo que um recebe até o momento em que este paga o doador. Se as relações "comerciais" são as que impedem moralmente a explosão de conflitos garantindo alianças, então

deveríamos não somente procurar mecanismos que obriguem ou motivem os homens (...) a pagar suas dívidas. Deveríamos também esperar encontrar mecanismos que induzam as pessoas a permanecer socialmente endividadas umas às outras e que inibam seu pagamento completo. (:175)

A dívida não é infinita, mas é reversível, como sugeriu o próprio Gregory (1982). São, para usar a terminologia de Deleuze e Guattari, blocos abertos de dívidas. As alianças, assim como a filiação estendida, aparece como as duas formas do "capital primitivo": um estoque ou capital fixo da filiação, um capital circulante ou "blocos móveis de dívidas". A aliança, dizem os autores, é "política e econômica e exprime o poder enquanto não se confunde com a hierarquia", com a administração, domínios do filiativo, nem se deduz delas (Deleuze \& Guattari,1994: 172). E os resultados dessa economia, como também afirma Bourdieu, não podem ser os do lucro nu. Segundo Deleuze e Guattari, o que move essa economia,

consiste em uma verdadeira mais-valia de código: cada destacamento de cadeia produz, de um lado ou de outro nos fluxos de produção, dos fenômenos de excesso e de falta e de acumulação, que se encontram compensados por elementos não trocáveis do tipo prestígio adquirido ou consumo distribuído. (: 176) 
No que toca a questão da reciprocidade como fundadora de relações, creio mesmo que se possa situar ainda um problema já aqui referido: para que uma relação de troca, de reciprocidade, seja possível, é preciso que algo a viabilize. Não são estranhas aos antropólogos as relações que exigem ou permitem as trocas. Malinowski deixa bastante claro que apenas certos tipos de pessoas participam do kula exterior. São chefes. Deles é esperado que participem e é exigido que façam circular seus objetos de valor. Não com qualquer pessoa, mas com iguais. Entre as tribos do Noroeste norte-americano, apenas de chefes é esperada a destruição de objetos durante os potlatch e os convites são feitos apenas entre seus iguais. O problema do desafio entre os Cabília já foi referido acima e os exemplos podem ser multiplicados à vontade. Uma relação supõe e exige a relação de dons. Não se troca coisas com qualquer pessoa. Antes das relações de dons há uma relação de poder. É preciso dar, receber e retribuir, mas apenas com um certo tipo de pessoas que estabelece com alguém um certo tipo de relação.

\section{Paul Veyne, o dom e o poder}

Diferente das demais é a abordagem de Paul Veyne (1974 e 1995). Tudo se desenvolve em torno de uma crítica à classificação de Karl Polanyi entre sociedades de mercado e sociedades sem mercado. Segundo Veyne, a conceptualização de Polanyi não explica nada. "Uma vez reconhecido que o potlatch, a Seguridade social, as obras pias e caridosas e 'o pão e o circo' são redistribuição, tudo fica por fazer' (1974: 1375). Haverá distribuição sempre que houver troca sem que haja mercado; a redistribuição é "uma noção negativa" (1995: 76). Ora, a oposição entre redistribuição e mercado não é feita no mesmo plano, já que a primeira não é o mercado, "mas uma redistribuição difere tanto de uma outra quanto do mercado (...) as redistribuições se fazem de igual a igual, de cima para baixo e de baixo para cima” (1974: 1375). 
Revista de Antropologia, São Paulo, USP, 2001, v. 44 nº 1.

Além disso, segue Veyne, esta noção é "mal recortada". Ela não é o escambo, mas tampouco é a troca monetária. Assim, o autor propõe ele próprio uma definição de redistribuição:

diremos que há redistribuição numa sociedade se algumas transferências são obrigatórias e sem contrapartida e se o objetivo destas transferências é assegurar aos desfavorecidos, sejam quem forem, a satisfação de necessidades que a sociedade considerada tem como indispensáveis. (1995: 92)

Que se reduza o problema para o da reciprocidade, ela mesma aparece com diversos sentidos. Usá-la é "pintar de um colorido uniforme realidades heterogêneas entre elas" e segue ele:

Há reciprocidade (...) quando vizinhos se reúnem em rodízio para cultivar seus campos em troca de retorno (...). Mas se se fala ainda de reciprocidade quando a corvéia real passa para arrastar em troca a benção do chefe, neste caso haverá reciprocidade quando um cidadão francês que paga o imposto recebe "em troca" o reconhecimento da França eterna. (1974: 1376)

Assim, o que é o dom, o que é a prestação, o que é a troca? O dom, diz Veyne, compreende a coisa dada e o ato de dar. Não se trata, ao contrário da troca, de extrair da coisa uma satisfação. A fonte de satisfação é a relação com o beneficiário. O dom não visa obter dons, mas "sacrificar uma satisfação material para satisfazer uma relação pessoal” (1995: 83). Não importa se há circulação de bens de lado a lado, "haverá dom autêntico e não troca disfarçada se os laços que tenho ou que crio como parceiro me importam mais que seu contradom. É em virtude desses laços que dou meu presente" (1995: 83). No entanto, em Veyne, não é o presente que cria a relação ou estabelece a sua natureza: "o ato de dar só é um episódio destas relações em que sacrifico uma satisfação material aos sentimentos que me inspira o meu parceiro" (idem). Mas a afeição, a admiração já estão dadas: "o dom verdadeiro é o episódio de uma relação de amizade, de deferência, de proteção, de respeito" (: 84).

No próprio interior de uma relação de reciprocidade há variações e ambigüidades. Não se poderia constituir uma classificação dura tal 
como a de Sahlins sem, também, "pintar de um colorido uniforme realidades heterogêneas entre elas". Uma relação entre vendedor e comprador é uma reciprocidade negativa? E no caso dos "parceiros comerciais", como lembra algures Paul Veyne? A reciprocidade é negativa ou generalizada?

O tema da compra de eleitores em Roma deixa perceber melhor que para Veyne a reciprocidade não funda uma relação. Os eleitores comprados em Roma não se vendiam para qualquer um. Por um lado porque não eram pobres cidadãos que se deixariam comprar a baixos preços. Mas, sobretudo, porque reservavam a prerrogativa de escolher a quem se vender. A cortesã, diz Veyne, não é prostituta, tem seus preferidos, sua relação está previamente constituída (1995: 400). Um dos fatores que constituíam o possível comprador era o prestígio, cujos componentes eram o nascimento, o mérito pessoal, a liberalidade, o número de partidários, entre outros. E não há como justificar a superioridade das posições referindo-se simplesmente à generosidade. Nem sempre quem dá assume a posição de domínio. As doações de homenagem são feitas pelos inferiores socialmente e por serem inferiores devem prestar suas homenagens em espécie. E o fato de darem jamais irá transformá-los em superiores.

\section{Dialética, reconhecimento e nihilismo: o binário, o total e o homogêneo}

Um dos problemas das teorias da reciprocidade situa-se na tentativa obcecada de totalizar uma multiplicidade não totalizável, de homogeneizar uma heterogeneidade, de enfeixar uma multiplicidade de linhas.

Se para Lévi-Strauss o fundamental é a circulação e a troca, para Deleuze e Guattari, são o fluxo e o corte. Já não há mulheres que circulam e que se troca. Há fluxo de mulheres constituído sobre um 
código que o corta, libera, direciona, segundo sua idade, clã, tribo (cursos, 16/11/71) ${ }^{11}$. O problema é de emissão e corte, não mais de circulação e troca. Substitui-se o estruturalismo e o troquismo pelo maquinismo. Em Deleuze e Guattari, os códigos são feitos de pedaços, eles misturam signos, conectam elementos diversos. Um código é um "sistema de relações indiretas entre fluxos codificados" (idem). As unidades dos códigos são blocos finitos funcionando sempre em desequilíbrio. O projeto de Lévi-Strauss é unificador e instituidor da idéia da troca em um sistema aberto, formado por três elementos heterogêneos. Todas as possibilidade de "conexões maquínicas livres" estão irremediavelmente fechadas. Ao contrário, o modelo que privilegia a heterogeneidade, o do "rizoma", o modelo nômade, é conectável à vontade, está em constante produção, é desmontável, reversível, é um sistema aberto. É o domínio das conexões maquínicas, "a-significantes", que põem em relação "regimes de signos" heterogêneos e se opõem às conexões mecânicas e finalistas (cursos, 14/05/73 e 1994).

Se Lévi-Strauss planta a árvore, a seqüência é prenha de ramificações. São os complementos de Mauss. Neles, se por vezes encontramos críticas à totalização levistraussiana, as idéias de reconhecimento, de dialética e, por conseqüência, de nihilismo sempre estão presentes. Qual seria o material de base de todas estas abordagens antropológicas da reciprocidade? De onde vêm essas idéias segundo as quais só é possível encontrar Hegel no fim do caminho do dom, do potlatch, do kula e de outros festivais nos quais reinam a generosidade, a liberalidade e o desapego aos bens materiais? Como é possível que, para onde quer que se olhe, só se veja o valor do trabalho do negativo e o homogêneo?

No livro sobre Nietzsche (Deleuze, 1998) o grande inimigo é a dialética. "O pluralismo tem por vezes aparências dialéticas; ele é o seu inimigo mais violento, o único inimigo profundo" (: 9). A explicação de Deleuze se desenvolve com base na teoria das forças. Por sua própria essência, uma força sempre está em relação com uma outra força. Como em toda relação de forças há um diferencial, uma delas obedece e a 
outra comanda. Segundo Deleuze, em Nietzsche esta última não age sobre a outra negando-a; ela afirma-se a si própria. Não existe propriamente negativo ou negação, apenas afirmação e gozo da diferença afirmada. "O que uma vontade quer é afirmar a sua diferença" e não negar uma outra. 'O 'sim' de Nietzsche se opõe ao 'não' dialético; a afirmação, à negação dialética; a diferença, à contradição" (: 10).

$\mathrm{O}$ que quer, pergunta Deleuze, esta vontade que quer a dialética? A vontade dialética é apresentada como uma força incapacitada da ação, força reativa. Incapaz de afirmar a sua diferença, ela coloca "o elemento negativo em primeiro plano em sua relação com o outro" (idem). É o problema da moral do escravo já referida acima. Do ponto de vista do senhor, a contradição e o negativo são produtos secundários. Na relação senhor-escravo, do ponto de vista do primeiro, o fundamental é a afirmação da potência. Do ponto de vista do escravo, é a representação da potência. O escravo representa a superioridade no reconhecimento. "O que as vontades querem em Hegel é fazer reconhecer sua potência, representar sua potência” (: 12).

Desse ponto de vista, a perspectiva de Bourdieu (1988) a respeito das relações de honra e vingança entre os Cabília e do problema do "capital simbólico" gira em torno do reconhecimento. A finalidade das repostas e da acumulação é a capitalização de uma e outra em torno do reconhecimento recebido ou negado segundo a reação ou nãoreação a um desafio; é a capitalização de um modo de lidar com as riquezas (a generosidade, a ostentação) que repercutem coletivamente. E se o Cabília entende-se como superior, isto não quer dizer que ele pretenda obter reconhecimento. Talvez a compreensão de superioridade de Bourdieu exprima a relação escravo-senhor:

O que nos apresentam como a própria potência é somente a representação que o escravo se faz da potência. O que nos apresentam como o senhor é a idéia que dele faz o escravo, é idéia que o escravo faz de si mesmo quando ele se imagina no lugar do senhor. Por que os filósofos aceitaram esta falsa imagem do senhor que parece apenas com o escravo triunfante? (Deleuze, 1998: 91-2) 
Uma perspectiva que privilegia não a superioridade, mas a sua representação, que exige uma "comparação das consciências" e "que um motivo corresponda à vontade de potência que sirva também de motor de comparação: a vaidade, o orgulho, o amor próprio, a ostentação ou mesmo o sentimento de inferioridade".

Seria possível fazer-se uma etnografia nietzscheana da honra entre os Cabília? Seria possível, em vez de se pensar a representação da potência e o reconhecimento do sujeito da ação por uma outra consciência, pensar-se a resposta e a não-resposta através das relações entre forças de natureza diferentes? Quando o conjunto das forças reativas é acionado pelas ativas e se forma uma resposta? Quando, ao contrário, as forças reativas não são capazes de ser acionadas, em virtude do enfraquecimento das forças ativas, etc.? Que conjunto de agenciamentos permite que se recuse a resposta, até que se atinja o limite? Ou então, como prefere Bourdieu, tudo gira em torno da representação que uma parte faz da potência da outra?

O binário, o total, o reconhecimento desembocam no homogêneo, no equilíbrio, no nihilismo. As relações de forças são apagadas em proveito de uma tendência ao estável, mesmo que seja uma tendência constantemente contrariada. São postas em segundo plano em proveito da consciência de si, do sujeito, da representação e do reconhecimento. Salvo por uma ou outra exceção, as poucas teorias antropológicas (e não só antropológicas) apresentadas aqui acabam no equilíbrio. Mesmo Georges Bataille, ao levar para o campo das sociedades humanas a sua teoria da "parte maldita", não consegue se desvencilhar da recompensa obtida pelo ato generoso:

Se os recursos que detém são redutíveis a quantidades de energia, o homem não pode reservá-los incessantemente para os fins de um crescimento que não pode ser infinito. É preciso que desperdice o excedente, mas ele permanece ávido de adquirir, mesmo quando faz o contrário, e transforma o próprio desperdício em objeto de aquisição. (1975: 110)

Capital simbólico em termos de Bataille, o desperdício tem como fim último o reconhecimento do outro. A destruição deve ser feita diante 
do outro porque "aquele que dá adquire efetivamente aos olhos do outro o poder de dar ou de destruir" (: 107). A argumentação gira em torno da negação do uso dos bens e não da afirmação de uma potência, de uma afirmação de si sobre os bens. A teoria é a da "contradição". A dilapidação confere prestígio e posição àquele que destrói. Pois se de dilapidação se trata, "aquisição é o fim último do potlatch" (: 109).

É curioso notar como a teoria da destruição não resistiu a setenta páginas: "As conseqüências na ordem da aquisição são apenas o resultado não desejado", dizia ele, "de um processo dirigido em sentido contrário" (: 36). De que serve a destruição da parte maldita senão para superar a crise, ultrapassar a instabilidade? A festa não aparece como descongestionante de uma energia que põe todo o sistema em perigoso desequilíbrio (: 62)?

O equilíbrio e a estabilidade, a homeostase. Segundo Deleuze, são estes os principais problemas entre Nietzsche e a ciência: "sua crítica se dá em três planos: contra a identidade lógica, contra a igualdade matemática, contra o equilíbrio físico" (1998: 51). Trata-se de uma crítica para recusar o cancelamento das diferenças quantitativas, ou seja, uma luta contra o equilíbrio, contra a estabilidade. E de que instrumento, pergunta Deleuze, a ciência lança mão para criar-se uma perspectiva nihilista do mundo? A compreensão científica do mundo se faz, responde ele, através das forças reativas, das forças de adaptação, de compensação, de re-ação. A perspectiva reativa do mundo impede que se veja nos fenômenos ditos de reciprocidade, de gasto improdutivo, a afirmação de uma força sobre outra. Os sujeitos, as identidades, as trocas, as teorias antropológicas, enfim, sempre acabaram por esconder o combate entre as forças na afirmação das suas diferenças. Tal perspectiva consiste em perceber os esforços para reequilibrar uma dada situação momentaneamente instável. Tal é a perspectiva de LéviStrauss em relação à guerra nas sociedades primitivas. Ou então ela se apresenta como a explicação de um processo civilizador. A abordagem de Sahlins é extremamente clara: o dom não serve para afirmar uma 
diferença; serve como um contrato no sentido de estabilizar uma situação original caótica. As teorias que apontam a reciprocidade fundadora da sociedade ou de uma dada relação social são freqüentemente mitos de origem e a "fundação" é a vitória da ordem (estabilidade) sobre o caos inicial (desequilíbrio).

As teorias de fundação supõem igualmente uma teoria da utilidade: a reciprocidade serve tal ou qual coisa. Dar tem em sua origem a utilidade de fundar a sociedade ou tal relação social, criar hierarquia e posição. Mas aqui se confunde origem com utilidade. E, se se cancela a confusão entre utilidade e origem, não é mais possível se pensar no dom de forma homogênea. A partir de então, o dom serve às forças que dão a ele um sentido, segundo os agenciamentos em questão, segundo as afecções postas em jogo. Saímos dos campos fundadores para os campos descritivos e explicativos. É assim que Veyne, como foi dito acima, pôde conferir ao ato da redistribuição uma grande diversidade de sentidos. Bem como pôde-se conferir ao ato de dar muitas "utilidades": dar como homenagem, dar como imposição, dar para afirmar a superioridade, etc.

\section{Conclusão}

As diversas formas de pensar o dom negligenciaram determinadas possibilidades. Certa perspectiva hegeliana do mundo as teria impossibilitado. A introdução de determinados conceitos introduzidos na Filosofia por Nietzsche podem liberar essas possibilidades. Trata-se antes de mais nada de objetivos, abordagens, perspectivas e interesses muito distintos dos anteriores. Apenas para resumi-los, eu diria que no caso das abordagens tradicionais tratou-se de procurar o equilíbrio e a homeostase sujacentes ao movimento e ao desequilíbrio permanente das forças sociais. O dom foi a armadura encontrada para colocá-las na forma. No caso da abordagem nietzscheana trata-se de procurar o movimento e o desequilibrio, o combate, que se escondem sob a aparente estabilidade. 


\section{Notas}

1 Todos estes textos e resumos de cursos, assim como os que se seguirão, encontram-se em CEuvres 3.

2 Para um histórico dessa influência, mas com um sentido diferente do apontado aqui, ver Sigaud (1999).

3 “(...) constitui uma regra, mas a única regra social que possui, ao mesmo tempo, um caráter de universalidade” (Lévi-Strauss, 1971[1966]: 10).

4 "A sociedade civil pôs fim ao estado de natureza, mas não à natureza humana" (Sahlins, 1976b: 232).

5 Este contratualismo não é originalidade de Mauss em seu tempo. Seu colega de Année Sociologique, Georges Davy, desenvolve uma teoria contratualista da qual o "Ensaio" é considerado por alguns comentaristas como uma continuação (Karsenti, 1994: 35; Lefort, 1979: 23). E o próprio Mauss: "O presente trabalho faz parte da série de pesquisas que perseguimos desde muito tempo, o Sr. Davy e eu (...)" (1993: 149).

6 Como por exemplo em Gouldner a respeito da clientela: “(...) a estima que vai ao homem generoso é unilateral, é assim que se admite utilmente a generosidade entre os mecanismos de esboço de poder, porque ela cria uma clientela" (1960).

7 John Lubbock, Otto Caspari, Joseph Koller e Albert H. Post são alguns deles (Andler, 1979, vol. II: 537).

8 Para uma breve porém esclarecedora apresentação das teorias transformacionistas (e do organismo como lugar de combate) destes dois autores, assim como as teorias de Alfred Espinas e Theodosius Ribot - igualmente importantes para o pensamento de Nietzsche -, ver Andler (1979, vol. II: 525-32).

9 Genealogia da moral, sobretudo I e II.

10 “(...) é o ato fundamental da sociedade: codificar os fluxos e tratar como inimigo o que, em relação a ela, se apresenta como um fluxo não codificável(...)" (cursos, 16/11/1971). 
11 "O que se passa sobre o corpo de uma sociedade? São sempre fluxos, e uma pessoa é sempre um corte de fluxos. Uma pessoa é sempre um ponto de partida para uma produção de fluxos de qualquer tipo; ou então uma intercepção de vários fluxos" (cursos, 16/11/71).

\title{
Agradecimentos
}

Agradeço ao professor Marcio Goldman pela leitura atenta do artigo e pelas valiosas sugestões por ele fornecidas. Sou grato também a Luís Takayama pela leitura e pelas dúvidas que me apresentou acerca do texto. Todas as afirmações aqui contidas são, no entanto, de minha inteira responsabilidade.

\section{Bibliografia}

\author{
ANDLER, C. \\ 1979 [1958] Nietzsche sa vie et sa pensée, Paris, Gallimard, 3 vol.
}

BATAILLE, G.

1975 [1967] A parte maldita, Rio de Janeiro, Imago.

BEAUCAGE, P.

1995 "Echange et Societé: avant et aprés Mauss", Anthropologie et Societés, vol. 19(1-2).

BOURDIEU, P.

1988 [1965] “O sentimento da honra na sociedade cabília”, in PERISTIANI, J. G. (ed.) Honra e vergonha - valores das sociedades mediterrânicas, Lisboa, Calouste Gulbenkian. 
Jorge Luiz Mattar Villela. A dívida e a diferençA

1994 [1980] Le sens pratique, Paris, Minuit.

1996 "Marginália. Algumas notas adicionais sobre o dom", Mana, vol. 2(2).

DELEUZE, G.

1980[1972] L'Anti-CEdipe, Paris, Minuit.

1998[1962] “Nietzsche et la philosophie", Quadrige, Paris, PUF.

Cursos em Vincennes (Anti-CEdipe e Mille plateaux).

DELEUZE, G. \& GUATTARI, F.

1994 [1980] Mille plateaux, Paris, Minuit.

FAURE, E.

1964 Les constructeurs, Paris, Gonthier.

FOURNIER, M.

1994 MarcelMauss, Paris, Fayard.

GOUDLNER, A.

1960 "The Norm of Reciprocity: a preliminary statement", American Sociological Review, vol. 25(2).

GREGORY, C.

1982 Gifts and Commodities, Academic Press, Londres.

KARADY, V.

1994 [1969] Marcel Mauss CEuvres, Paris, Minuit.

KARSENTI, B.

"Marcel Mauss: le fait social total", Philosophies, Paris, PUF. 
LEFORT, C.

1979 [1951] “A troca e a luta dos homens", in As formas da história - ensaio de antropologia, São Paulo, Brasiliense.

LÉVI-STRAUSS, C.

1971[1966] Les structures élementaires de la parenté, Paris, Mouton.

1993[1950] “Introduction à l'oeuvre de Marcel Mauss”, in Sociologie et Anthropologie, Paris, PUF, Quadrige.

MAUSS, M.

1993[1925] "Essai sur le don. Forme et raison de l’echange dans les sociétés archaïques", in Sociologie et Anthropologie, Paris, PUF, Quadrige.

1994a[1921] “Une ancienne forme de contrat chez le traces", in KARADY, V. Marcel Mauss QEuvres, Paris, Minuit.

1994b[1924] “Gift-Gift”, in KARADY, V. Marcel Mauss Eewres, Paris, Minuit.

NIETZSCHE, F.

s.d. [1886] Além do bem e do mal, São Paulo, Hemus.

1912 [1888] Lagenealogie de la moral, Paris, Mercure de France.

PARRY, J.

1984

"The Gift, the Indian Gift and the 'Indian Gift"', Man, vol. 21(3), New Series.

SAHLINS, M.

1976a[1965] 'De la sociologie de l'echange primitif', in Âge de Pierre, âge d'Abondance, Paris, Gallimard, Sciences Humaines.

1976b[1968] “L'esprit du don”, in Âge de Pierre, âge d'Abondance, Paris, Gallimard, Sciences Humaines. 
SIGAUD, L.

1999 “As vicissitudes do 'Ensaio sobre o dom”, Mana, vol. 5(2).

SIMONIS, Y.

1979[1968] Lévi-Strauss on a paixão do incesto, Lisboa, Moraes.

WEINER, A.

1992 Inalienable Possessions. The Paradox of Keepeing-While-Giving, Berkely, Univ. of California Press.

VEYNE, P.

1974 "Pour une histoire anthropologique: la notion de reciprocité, (Debat). Annales E.S.C. (6).

1995 [1976] Le pain et le cirque - Sociologie historique d'un pluralisme politique, Paris, Seuil, Points Histoire.

\begin{abstract}
The goal of this article is to propose alternative reflections to the notion of "gift" as an anthropological concept, free of the qualities of equivalence, homeostasis, dialectics, and acknowledgment. As the present text suggests, these elements are essential in several interpretations of Marcel Mauss's Essai sur le Don, as well as various anthropological interpretations of the concept of reciprocity. I have approached this material through the use of concepts presented by authors such as Nietzsche in his Genealogy of Moral, and Gilles Deleuze and Felix Guattari's Anti-Oedipe, who resist subjacent hegelianism in the construction and use of gift and reciprocity referred to above.
\end{abstract}

KEY-WORDS: Reciprocity, gift, anthropological theory.

Recebido em setembro de 2000. 